\author{
By:
}

S.K. Murthy

W.F. Weldon

S.B. Pratap

W. Gagnon

Digest of Technical Papers of the 9th IEEE Pulsed Power Conference, Albuquerque, NM, June 21-23, 1993, p. 44

Center for Electromechanics

The University of Texas at Austin

PRC, Mail Code R7000

Austin, TX 78712

(512) 471-4496 


\title{
POWER SUPPLIES FOR AIRBORNE LASER SYSTEMS
}

\author{
S.K. Murthy, W.F. Weldon, and S.B. Pratap \\ Center for Electromechanics \\ The University of Texas at Austin \\ BRC, Mail Code 77000 \\ Austin, TX 78712 \\ W. Gagnon \\ Lawrence Livermore National Laboratories (consultant)
}

\begin{abstract}
This paper investigates the power supply options for an airborne laser system (solid state laser diodes). The application demands a power supply capable of a high repetition rate $(1,428$ pulses per engagement over $2 \mathrm{~s}$ ) and delivering total energy of $20 \mathrm{MJ}$ (i.e. $14 \mathrm{~kJ}$ per pulse). The high repetition rate precludes the use of capacitors Hence rotating machines storing inertial energy appear to be the most viable option.

In this paper the compensated pulsed alternator (compulsator) invented by the Center for Electromechanics at the University of Texas (CEM-UT) at Austin is examined as a possible power supply option for the above application. The laser system is characterized as a $1.25 \mathrm{~m} \Omega$ resistive load. In the past the compulsator has been examined essentially for inductive loads like the railgun and hence the analysis presented here throws new light on the capabilities of the compulsator. Several configurations involving the compulsator are evaluated in this paper viz. two machines operating in parallel, a single machine storing all the energy and an external flywheel storing the required energy with compulsator serving as a energy conversion device. The paper explores the lower limits on the compulsator size and weight for the different configurations
\end{abstract}

\section{INTRODUCTION}

The compensated pulsed alternator or the compulsator, invented by the Center for Electromechanics at the University of Texas at Austin (CEM-UT) has been analyzed and utilized as a potential power supply for electromagnetic launchers (railguns) since 1978 The railgun is primarily an inductive load and therefore the use of a compulsator to supply a resistive load has not been received adequate attention. The compulsator is a device which utilizes compensation to reduce its internal impedance. There are several forms of compensation [1], passive compensation being the simplest A passively compensated machine uses a continuous conducting shield which is at rest with respect to the field excitation of the machine. The static exciting field diffuses through the shield and induces a voltage in the spinning armature conductors. Passive compensation is achieved when compensating currents are induced in the shield during a discharge. Since the shield is continuous, compensation is provided equally in all rotor positions resulting in a constant low inductance. The passive machine will generate pulses which are basically sinusoidal in shape. Thus the passive compulsator is capable of maximizing power outpur by minimizing internal impedince.

This paper examines the use of a passive compulsator to supply a laser system load characterized as a $1.25 \mathrm{~m} \Omega$ resistor. The ideal pulse shape for the application is square. This would suggest the use of a selective passive machine [2], which allows for the tailoring of a variety of pulse shapes. However, the load $(1.25 \mathrm{~m} \Omega)$ being highly resistive will dominate the circuit impedance and no pulse shaping cun be realized. Therefore the passive machine is used as a power supply for this application. The application requires a pulse with a full width to half maximum (FWHM) requirement of 350 to $500 \mu \mathrm{s}$. The FWHM specitication along with the requirement of 1,428 pulses over 2 s determines the electrical frequency of the compulsator for this application. The compulsator is required to have an electrical frequency of $714 \mathrm{~Hz}$ (with FWHM of $460 \mu \mathrm{s}$ ).

Each pulse delivers $14 \mathrm{~kJ}$ for energy resulting in al total energy of $20 \mathrm{MJ}$ over $2 \mathrm{~s}$ to the load. The energy requirement specifies the lond peak current to be $180 \mathrm{kA}$. The compulsator open circuit voltage is fixed at $300 \mathrm{~V}$. Table 1 details the load requirements and the compulsator description. The different configurations and options available with the compulsator as the power supply are discussed below

Table 1 . Load and compulsator descriptions

\begin{tabular}{|c|c|}
\hline Load Specifications & \\
\hline FWhlM of current pulse & 350 to $500 \mu \mathrm{s}$ \\
\hline $\begin{array}{c}\text { Energy per pulse to load } \\
\text { engagement } \\
\text { Time between pulses }\end{array}$ & $14 \mathrm{~kJ}$ \\
\hline Duration of engagement & 1428 \\
\hline $\begin{array}{c}\text { Total energy to load per } \\
\text { engagement }\end{array}$ & $20 \mathrm{MJ}$ \\
\hline Resistive load & $1.25 \mathrm{~ms} \Omega$ \\
\hline Compulsator Description & \\
\hline $\begin{array}{c}\text { Type of machine } \\
\text { Type of excitation }\end{array}$ & $\begin{array}{c}\text { Cossive } \\
\text { Compulsator }\end{array}$ \\
\hline Pulse shape & Permanent Magnet \\
\hline Trigger point & Sinusoidal \\
\hline Electrical frequency & Zero crossing \\
\hline FWHM & $714 \mathrm{~Hz}$ \\
\hline
\end{tabular}




\section{CONFIGURATIONS FOR THE COMPULSATOR BASED POWER SUPPLY}

The two main configurations evaluated for the compulsator are the single machine vs. two machines operating in parallel. Figure 1 indicates the prime mover options for the two machine configuration evaluated for the application detailed in this paper The percentage change in speed is determined by the drive available for the compulsator. A turbine as the prime mover (with a gearbox drive) would allow only $5 \%$ drop in speed. The two machine option allows convenient operation (each machine can be located near the aircraft engines) of the $400 \mathrm{hp}$ engines on the aircraft as the prime mover. The single machine configuration (fig. 2) however requires the use of a hydraulic pump (or electric generator) driving an hydraulic motor (or electric motor). The use of hydraulic pumpmotor drive (or electric generator-motor drive) allows for a larger variation in speed during a discharge

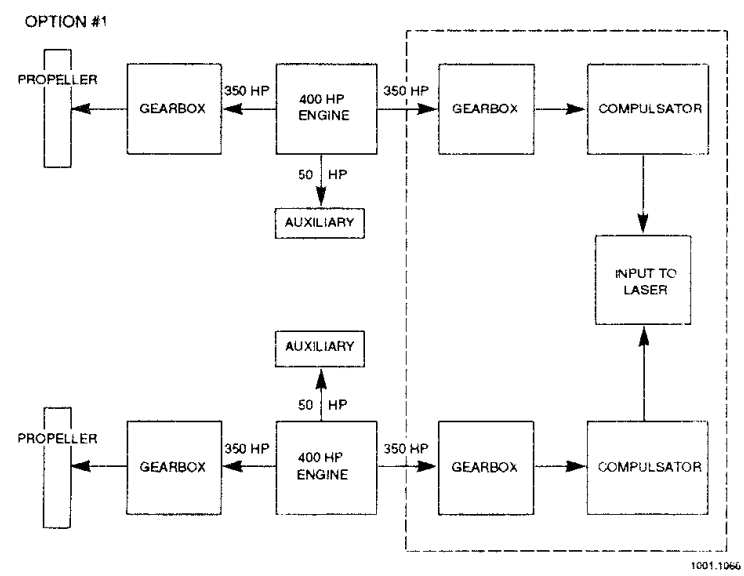

Figure 1. Motoring option for two compulsator configuration

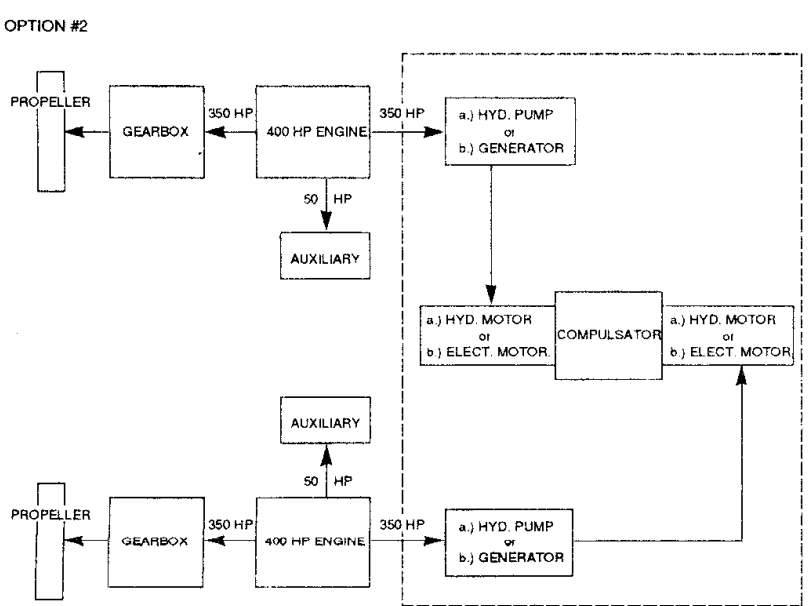

Figure 2. Motoring options for one compulsator configuration
Figure 3 shows the different compulsator options investigated in this paper. The change in speed indicated in the figure is over the entire engagement $(1,428$ pulses $)$. The $25 \%$ change in speed with the single machine configuration was analyzed to arrive at an estimate for the lowest weight possible with a single compulsator

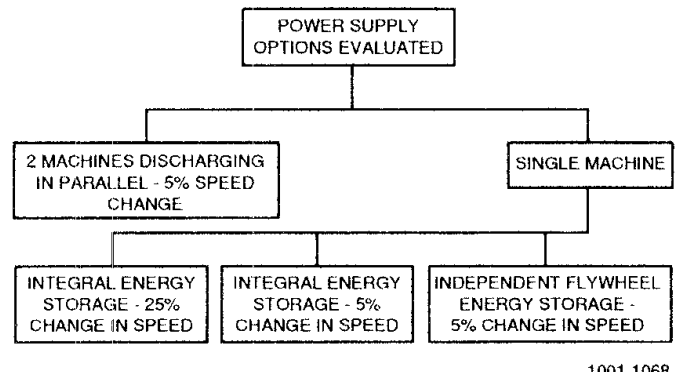

Figure 3. Power supply options evaluated for laser application

The high electrical frequency $(714 \mathrm{~Hz})$ of operation precludes the possibility of a two pole compulsator, which would be the most attractive configuration with respect to minimizing the mass of the power supply. The high tip speeds in a two pole configuration result in stress management problems (especially armature winding banding) and the two pole design also has a high magnetic signature. The four, six etc. pole configurations have the advantages of lower magnetic signature but have more mass because of lower rotor tip speeds. All compulsators examined in this paper are of the external rotor (shell) machine type.

\section{A) Two Machines Discharging in Parallel}

The stored energy requirement for this option can be calculated based on a speed change of $5 \%$ over one engagement and the total energy (20 MJ) to be delivered to the load. A discharge efficiency of $95 \%$ was assumed. Each machine stores $100 \mathrm{MJ}$. The four and six pole options were evaluated. The results of the evaluation are presented in table 2 . The machines represent the minimum mass choices. The compulsators were designed for high tip speeds (not exceeding $1,000 \mathrm{~m} / \mathrm{s}$ ) to maximize energy density. Also the machines are of the shell (external) rotor type. The design allows for a temperature rise of $95^{\circ} \mathrm{C}$ over one complete engagement. The six pole option is heavier as it spins at a lower tip speed but has the advantage of lower magnetic signature

Table 2. Two machines discharging in parallel; $5 \%$ change in speed over one engagement

\begin{tabular}{|c|c|c|c|}
\hline \multirow[b]{2}{*}{ Machine Parameters } & \multirow[b]{2}{*}{ Units } & \multicolumn{2}{|c|}{ Value } \\
\hline & & 4 pole & 6 pole \\
\hline Outer diameter & $\mathrm{m}$ & 0.88 & 1.16 \\
\hline Length & $m$ & 0.83 & 0.9 \\
\hline Stored energy & MJ & 100 & 100 \\
\hline Machine Speed & $\mathrm{rpm}$ & 21,420 & 14,280 \\
\hline Tip Speed & $\mathrm{m} / \mathrm{s}$ & 992 & 866 \\
\hline Peak open circuit voltage & $\mathrm{V}$ & 300 & 300 \\
\hline Discharge efficiency & $\%$ & 95.6 & 94.7 \\
\hline Mass & $\mathrm{kg}$ & 750 & 1014 \\
\hline
\end{tabular}


In general, the two machine option is always heavier than the single machine. But each of the two machines is smaller in size

\section{B) A Single Machine}

1) Integral energy storage and 5\% change in speed over one engagement: table 3 depicts the results of storing all the required energy $(200 \mathrm{MJ})$ in one machine for a $5 \%$ change in speed over one engagement. Again the four and six pole configurations are explored. Again the designs (table 3) represent the minimum mass options. The temperature rise and tip speed limitations are as mentioned above

Table 3. Single machine (integral energy storage); $5 \%$ change in speed over one engagement

\begin{tabular}{|c|c|c|c|}
\hline \multirow[b]{2}{*}{ Machine Parameters } & \multirow[b]{2}{*}{ Units } & \multicolumn{2}{|c|}{ Value } \\
\hline & & 4 pole & 6 pole \\
\hline Outer diameter & $\mathrm{m}$ & 0.90 & 1.3 \\
\hline Length & $m$ & 1.10 & 1.0 \\
\hline Stored energy & MJ & 200 & 200 \\
\hline Machine Speed & $\mathrm{rpm}$ & 21,420 & 14,280 \\
\hline Tip Speed & $\mathrm{m} / \mathrm{s}$ & 1,031 & 968 \\
\hline Peak open circuit voltage & $\mathrm{V}$ & 300 & 300 \\
\hline Discharge efficiency & $\%$ & 96.3 & 97.1 \\
\hline Mass & $\mathrm{kg}$ & 1,078 & 1,327 \\
\hline
\end{tabular}

2) Integral energy storage and $25 \%$ change in speed over one engagement: table 4 shows the four and six pole options each storing 50 MJ. These machines are designed to discharge almost $50 \%$ of the stored energy over one engagement. The mass of these machines are lower than the other options explored above

Table 4. Single machine (integral energy storage); $25 \%$ change in speed over one engagement

\begin{tabular}{|l|l|c|c|}
\hline \multirow{2}{*}{ Machine Parameters } & \multirow{2}{*}{ Units } & \multicolumn{2}{|c|}{ Value } \\
\cline { 3 - 4 } & 4 pole & 6 pole \\
\hline Outer diameter & $\mathrm{m}$ & 0.70 & 0.90 \\
\hline Length & $\mathrm{m}$ & 0.62 & 0.67 \\
\hline Stored energy & $\mathrm{MJ}$ & 50 & 50 \\
\hline Machine Speed & $\mathrm{rpm}$ & 21,420 & 14,280 \\
\hline Tip Speed & $\mathrm{m} / \mathrm{s}$ & 782 & 680 \\
\hline Peak open circuit voltage & $\mathrm{V}$ & 300 & 300 \\
\hline Discharge efficiency & $\%$ & 96.7 & 96 \\
\hline Mass & $\mathrm{kg}$ & 540 & 720 \\
\hline
\end{tabular}

All the designs presented previously are energy limited designs i.e. the machine mass is driven by energy storage requirements. A study was to conduct to appraise the effect of storing energy. independently, in a flywheel attached to the rotor of the compulsator. The size and mass of the compulsator was determined as a function of the energy stored in the rotor. Table 5 shows the minimum mass options. Two flywheels are used to store the required energy. The flywheels are also limited to a maximum of $1,000 \mathrm{~m} / \mathrm{s}$ in tip speed.
Table 5. Single machine- independent flywheel energy storage; $5 \%$ change in speed over one engagement

\begin{tabular}{|c|c|c|c|}
\hline \multirow[b]{2}{*}{ Machine Parameters } & \multirow[b]{2}{*}{ Units } & \multicolumn{2}{|c|}{ Value } \\
\hline & & 4 pole & 6 pole \\
\hline Outer diameter & $\mathrm{m}$ & 0.48 & 0.56 \\
\hline Length & $\mathrm{m}$ & 0.58 & 0.53 \\
\hline Stored energy & M] & 13 & 10 \\
\hline Machine Speed & rpm & 21,420 & 14,280 \\
\hline Tip Speed & $\mathrm{m} / \mathrm{s}$ & 548 & 417 \\
\hline Peak open circuit voltage & V & 300 & 300 \\
\hline Discharge efficiency & $\%$ & 96.2 & 94 \\
\hline Mass & $\mathrm{kg}$ & 393 & 460 \\
\hline FLYWHEEL (1 OF 2) & & & \\
\hline Outer diameter & $\mathrm{m}$ & 0.9 & 1.34 \\
\hline Length & $\mathrm{m}$ & 0.35 & 0.158 \\
\hline Stored energy & M] & 93.5 & 95 \\
\hline Tip Speed & $\mathrm{m} / \mathrm{s}$ & 1,000 & 1,000 \\
\hline Mass & $\mathrm{kg}$ & 353 & 370 \\
\hline $\begin{array}{l}\text { Total Mass } \\
\text { (machine }+2 \text { flywheels) }\end{array}$ & kg & 1,100 & 1,200 \\
\hline
\end{tabular}

Figures 4 to 7 summarize the results of the study. Figure 4 reflects the effect of the stored energy on the mass of the machine. As the energy stored in the machine decreases so does the size and the mass of the machine. However at energy levels below $10 \mathrm{MJ}$ the returns diminish. This is because as the size of the machine decreases the coupling between the armature and the field windings becomes poor (fig. 5), resulting in higher field ampere-tum requirement and consequently higher field coil mass (fig. 6). The designs evaluated in figure 4 were for a maximum field density $0.5 \mathrm{~T}$ at the armature winding. These designs also revealed that the internal impedance of the machine was insignificant in comparison to the $1.25 \mathrm{~m} \Omega$ load. Lowering the peak field to $0.25 \mathrm{~T}$ resulted in an increase in the armature conductors per pole and the internal impedance of the machine, thus affecting the performance of the machine. Increasing the peak flux density above $0.5 \mathrm{~T}$ increased the field coil mass and the mass of the machine indicating that the optimum value of the maximum flux density was between the two values. Figure 7 shows the component mass and total power supply mass vs. energy stored in the compulsator rotor.

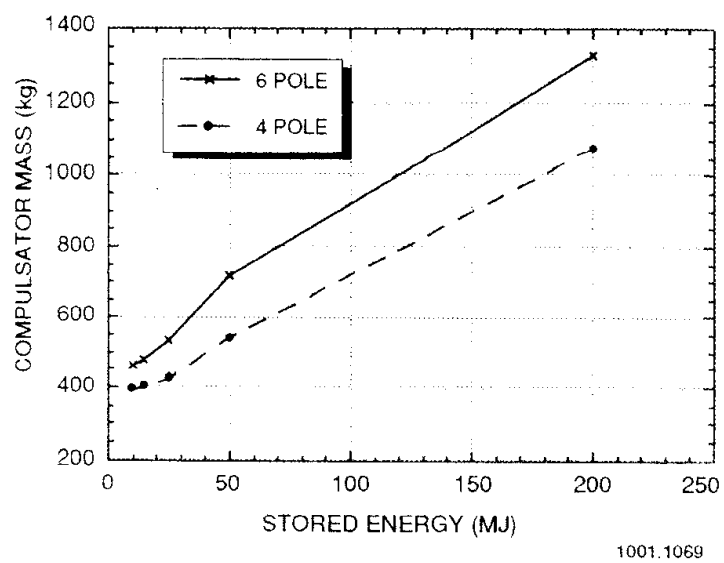

Figure 4. Mass of compulsator vs. stored inertial energy 


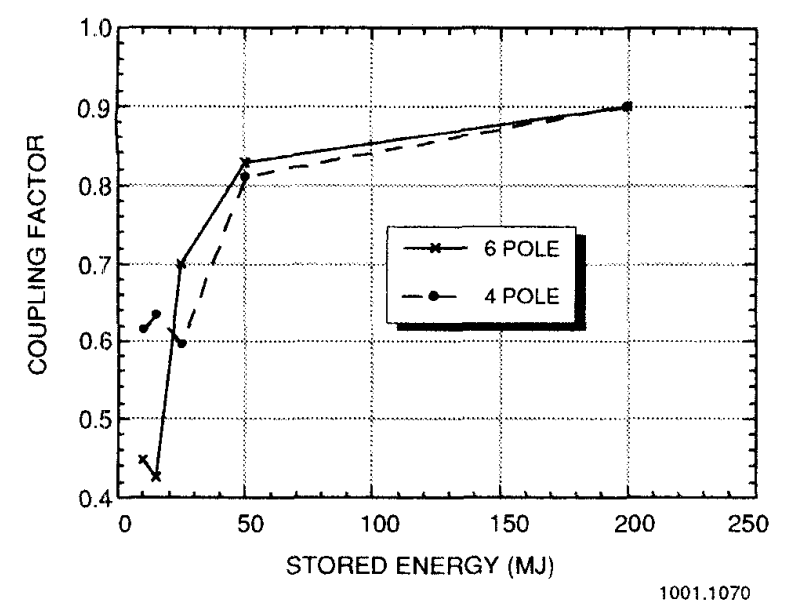

Figure 5. Coupling between field and armature windings vs. stored inertial energy

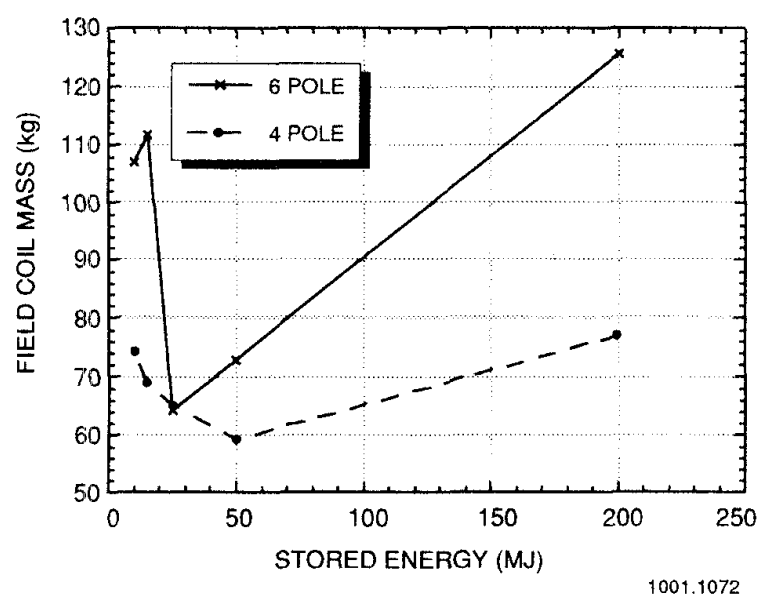

Figure 6. Field coil mass of compulsator vs. stored energy (inertial)

\section{CONCLUSIONS}

The paper sheds new light on the capabilities of the compulsator. It shows that the compulsator has potential to be used as a power supply for solid state laser diodes. The different configurations examined in the paper reveal the different factors which control the weight of the compulsator as the inertial energy stored is varied.

To conclude, the compulsator has several attractive features and further optimization of the design could lead to reducing the mass of the system. The external rotor (shell) machine is an interesting concept and requires detailed engineering.

\section{REFERENCES}

[1] S.B. Pratap, et al. "Compulsator Research at the University of Texas - An Overview," IEEE Transactions on Magnetics, vol. 25, no. 1, pp 529-537, January 1989.

[2] S.B. Pratap, K.-T Hsieh, M.D.Driga, and W.F. Weldon, "Advanced Compulsators for Railguns," IEEE Transactions on Magnetics, vol. 25, no. 1, pp 454-459, January 1989.

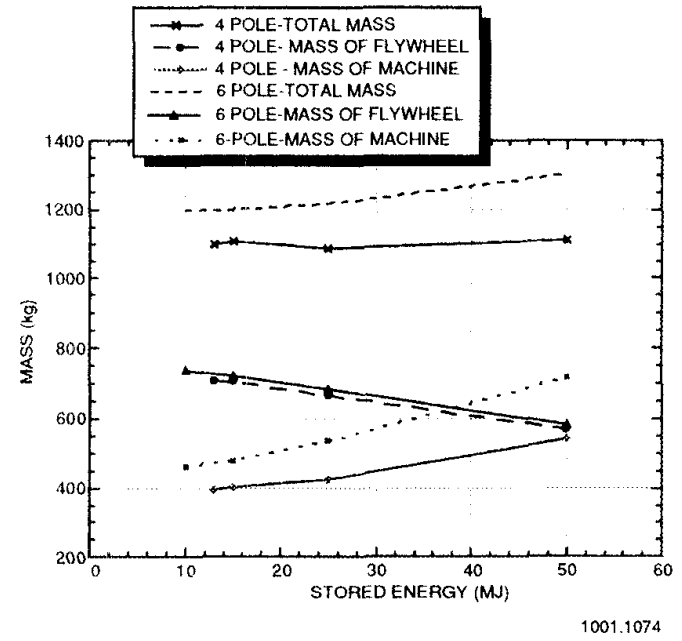

Figure 7. Component and total mass for independent energy storage 